\title{
Adapting and implementing the Wine in Moderation-Art de Vivre programme in Argentina
}

\author{
Natalia Alvarez ${ }^{1}$, Stylianos Filopoulos ${ }^{2}$, Ursula Fradera ${ }^{2}$, José Ramón Fernández ${ }^{3}$,' Juan Carlos Pina ${ }^{1}$, \\ and Patricia Ortiz ${ }^{1}$ \\ ${ }^{1}$ Bodegas de Argentina AC, Güemes 4474 piso $1^{\circ}$ - CABA, Argentina \\ ${ }^{2}$ Wine in Moderation-Art de Vivre (WIM) Aisbl, Avenue des Arts 43, 1040 Bruxelles, Belgium \\ ${ }^{3}$ Comité Européen des Entreprises Vins(CEEV), Avenue des Arts 43, 1040 Bruxelles, Belgium
}

\begin{abstract}
The Wine in Moderation-Art de Vivre (WIM) programme was officially launched in 2008 as the wine sector's contribution to the EU Alcohol \& Health Forum, within the framework of the EU strategy to support Member States in reducing alcohol-related harm. Building on the values of the "wine culture" and founded on information backed by science, broad education \& self-regulation, WIM aims at promoting moderate and responsible behavior in the consumption of wine as a social and cultural norm. Considering the global and national trends in the wine market, the drinking patterns and the alcohol \& health policy, Bodegas de Argentina (BAAC) decided to mobilize concrete actions to contribute to the reduction of alcohol related harm, by adapting and implementing the WIM programme in Argentina. BAAC decided to engage the whole national wine value chain in the WIM programme and empower them with necessary knowledge and tools to properly implement it and disseminate the WIM message. The first step was to adapt the WIM programme and message to the cultural and linguistic context respecting the programme's common approach and creating an action plan with 2 main phases. With the Argentinean wine value chain participating in WIM and having the proper skills to do, the challenge now lies in reaching consumer. The successful implementation in Argentina has set a milestone in WIM's international development.
\end{abstract}

\section{Introduction}

From the 16th century when the first vines were planted in Argentina, wine has been a key ingredient of the cultural and culinary heritage of Argentina. Vitiviniculture goes from north to south from $22^{\circ}$ a $42^{\circ}$ latitudes covering an area of 230.000 cultivated hectares consisting out of diverse terroirs [1].

Argentina is the fifth world wine producer and ranks ninth in wine exports globally. The domestic market is appraised at 1.200 million dollars, very similar to the external market, which is appraised at 1.260 million dollars. The wine sector thus brings an invaluable contribution to the Argentinean economy and employment [2].

Bodegas de Argentina (BAAC) is a business chamber that gathers the great majority of the country' $\mathrm{s}$ wineries. It has 260 members and was created in 2001 when Centro de Bodegueros de Mendoza (1935) and the Asociación Vitivinícola Argentina (1904) merged.

The wineries which are members represent $70 \%$ of the domestic market and $90 \%$ of the external market. Members range from traditional viticultural companies to smaller family companies. Among them are old family wineries, foreign investments, multinational companies, SMEs (small and medium enterprises), partnerships and cooperatives.

Argentina has seen similar changes to the Mediterranean wine producing countries in wine consumption, with the a decrease of the table wines consumption (20 million HL-10 million HL) (1979-2000) [4]. Today, the per capita wine consumption in Argentina reaches 24 litres, which is less than $1 / 3$ of the consumption in 1970 (90 lt/capita) [3,5].

The overall recorded per capita (15+ years) consumption of pure alcohol in litres in Argentina has dropped from 11.66 in 1990 to 8.15 in 2010 . Nonetheless, the recorded per capita alcohol remains one of the highest in the South America region.

While in the $1990,80.8 \%$ of the recorded per capita consumption $(15+$ years $)$ of pure alcohol was attributed to wine, this percentage has dropped to $48 \%$ in 2010 . During the same time alcohol consumption attributed to beer has increased from $11.8 \%$ to an $40.7 \%$ [6]. While in 2010 , the patterns of drinking scored $2-$ on a scale of 1 to 5 - based on the WHO system ( 1 being the least risky and 5 the most risky), showing an overall good drinking pattern, in terms of the years of life lost (YYL) index (based on alcohol-attributable years of life lost in a scale of 1 to 5 , with 1 being the least and 5 the most), Argentina scored 4 in 2012. This high score of YYL could be attributed to liver cirrhosis and alcohol related road accidents [7].

Today there is a growing concern from Health Authorities both at national and international level to tackle alcohol related harm with concrete Alcohol and Health policies and by including alcohol in the policies of fighting Non-communicable diseases.

This is an Open Access article distributed under the terms of the Creative Commons Attribution License 4.0, which permits unrestricted use, distribution, and reproduction in any medium, provided the original work is properly cited. 
Moderate responsible wine drinking is compatible with a healthy lifestyle and can provide enjoyment. A minority of consumers, however, misuses alcoholic beverages in a way that is associated with serious harm for themselves and those around them. The entire society has to take responsibility and all stakeholders need to participate in the prevention of such irresponsible drinking behaviors.

The wine sector recognizes the negative consequences of harmful and hazardous drinking patterns and supports initiatives, which reduce harmful alcohol related behavior. In order to address this issue, broad population based on statutory restrictions are often disproportionate and penalize the vast majority of adult consumers and legitimate economic activities and actors. Measures aimed at reducing harmful use of alcohol need to take into account the various specific national, cultural, situations, and focus on targeted local efforts supporting in particular:

- positive approaches to encourage responsible drinking patterns/moderate consumption as a social norm among those adults who choose to drink;

- education in the broadest sense of "life-skills" to promote sensible drinking patterns and cultural change in the approach to alcohol beverages and to reduce alcohol related harm;

- responsible and effective self-regulation.

The Wine in Moderation-Art de Vivre programme (WIM), officially launched in 2008, is the European wine sector's commitment to the European Alcohol and Health Forum to promote responsibility and moderation in wine consumption, contributing in a tangible and measurable manner to the EU Strategy to support the Member-States in reducing alcohol related harm. The WIM message and the programme's overall objectives and architecture are the same but the actions are adapted to national and local needs. It is implemented and coordinated at national level by national representative organizations of the wine sector. In 2011, with the launch of the 2nd commitment period, the WIM aisbl - a non for profit organization - was created to coordinate and support the development of the programme in Europe and worldwide. Today, the WIM aisbl counts 16 members (effective and observers) and WIM activities are developed in more than 20 countries.

In parallel, a number of multinational companies of alcoholic beverages launched a global action. (Global Commitments), setting a number of key commitments to reduce alcohol related harm with some of them being active in Argentina, too.

Taking into account the local consumption patterns and problems related to harmful use of alcohol the political environment and the market needs, BAAC, together with the Beer and Liqueurs 'Chambers, collaborated in a national campaign, called a "Alcoholic Beverages responsible consumer's rules" in 2012. The Nation's Health and Social Action Ministry, through COPAL (Coordinadora de las Industrias de Productos Alimenticios / Coordinator of the Alimentary Products Industries) has published this national campaign.

In 2013, BAAC decided to scale up action and contribute to the reduction of alcohol related harm by promoting responsible and moderate wine consumption in Argentina as a cultural and social norm, by developing a comprehensive approach on wine, health and social aspects, based on the unique attributes of wine, aimed at involving the whole wine sector.

\section{Methods}

The WIM programme was developed around 4 key objectives:

Objective 1: Disseminating a common message about moderation throughout the entire wine sector, using targeted communication materials, including brochures and presentations.

Objective 2: Educating key players and consumers about responsible consumption, through targeted education programmes, to encourage cultural change and to make moderation fashionable

Objective 3: Promoting responsible commercial communications, through the adoption of a common code of conduct for commercial communication, building on national self-regulatory codes.

Objective 4: Sharing best practice across the EU, by making all relevant scientific information available, and by stimulating identification of priority areas for additional independent research on health, social and cultural aspects of wine drinking in Europe.

To achieve these objectives WIM communicates a message of moderation and responsibility (WIM common message) based on 3 main pillars:

1. Wine Communication Standards-(WCS); self - regulation of commercial communication,

2. Art de Vivre - life skills; professionals and consumers education and training

3. Wine Information Council (WIC); exchange of good practices and scientific information.

Taking into account the structured approach and the achievements of the WIM movement [8], the common principles and objectives that WIM and BAAC share, BAAC decided in 2013 to join the WIM Association (Aisbl) as Observer member and adapt the WIM programme in Argentina to develop a comprehensive approach on wine, health and social aspects. BAAC became as such the first non - European member of WIM Association (WIM Aisbl) and Argentina the first country outside EU with a national WIM coordinator and a structured WIM programme.

Starting in 2011, BAAC initiated the dialogue on responsible consumption. A dedicated working committee that works in partnership with the other BAAC committees was created to communicate and coordinate the actions regarding responsible consumption within the wine industry and when BAAC joined WIM, the committee fully focused its work on planning, implementing, reporting and assessing the WIM program in Argentina. The committee is composed of representatives of different Wine Companies that joined the program and they are in charge of the WIM implementation plan in their own companies. In addition, a person was recruited to support the coordination of the Working Committee and of the WIM programme implementation. 
BAAC receives the support of the WIM aisbl, which provides the necessary guidance for the overall programme implementation in Argentina.

The goals of BAAC's Responsible Consumption Committee through the WIM programme are to:

- Motivate, engage and empower the whole wine value chain (wineries, companies and different entities) to adopt Social Responsible practices and communicate a message of moderation and responsibility.

- Promote a responsible behavior and a moderate wine consumption as a social and cultural norm; to prevent and reduce the harm caused by the abusive and hazardous consumption of alcoholic beverages.

- Position Argentina and the Argentinean wine sector as leading country/sector in the area of wine, health and social aspects.

BAAC developed a WIM national action plan for the period 2013-2014.

The plan focused on reaching out to the market with the WIM common message and engaging key stakeholders with the WIM programme.

Among the Key Stakeholder were:

- Wineries: Old family wineries, foreign investments, multinational companies, SMEs (small and medium enterprises), partnerships and cooperatives.

- Relevant trade associations or Chambers (e.g. CAVA, FEHGRA, AEGRA, COPAL, WofA).

- Authorities, Government Bodies and Institutions: (e.g. COVIAR, Traffic Safety, INV, AAS).

- Media/Press: (e.g. General, Specialized in food \& wines, CSR (Corporate Social Responsibility)).

- Training Providers (e.g. Wine and Gastronomy Academies).

- Other related Companies (e.g. Automotives, Car insurances, Mineral Waters, Laboratories, Prepaid Medicines).

The first step was to adapt the WIM programme and message to the cultural and linguistic context respecting the program's objectives and architecture. Therefore communication material (leaflets, brochures, etc.) were developed and then published.

Two big launching events took place in October 2013 (Mendoza and Buenos Aires), to mark the beginning of WIM in Argentina.

Efforts during the first phase of the action plan were focused on recruiting the majority of BAAC member to adhere to WIM and adopt the WIM message in their communication.

Special focus was placed in the recruitment of leading Argentinean wine companies that could set the example in the market.

Looking towards empowering their members with the necessary knowledge, BAAC organized a number of seminars and meetings to present and explain responsible drinking and ways of adapting and implementing the WIM program in their companies. For example: how to spread and communicate the WIM message in their social networks, actions and events.

BAAC has also placed considerable effort not only to communicate WIM to wider audiences through organizing events but also through events organized by the wine industry. Different strategies and approaches were implemented depending on the event and whether there was wine consumption, different strategies and responsible consumption actions, to communicate and ensure moderate and responsible drinking.

Among the approaches used was to regulate the consumption, to promote a responsible driver by giving incentives to the designated driver and to ensure that water is offered. In parallel, the WIM message was communicated through video spots to promote responsible behavior in wine drinking as a cultural habit. Focus was also put on highlighting that success of events and celebration depends on moderate and responsible wine consumption.

In 2014, during the second phase of the action plan, communication is due to scale up.

The media and communication plan of the 2nd phase of the action plan, include radio interviews and meetings, engagement of opinion leaders as well as newsletters dissemination.

Activities such as workshops and conferences for institutions and sommeliers in Buenos Aires, Mendoza and other regions of the country are programmed throughout the year. BAAC efforts are supported by the wineries that are part of the WIM programme.

Considering the success of the launching event, and in order to set the necessary milestone in the programme implementation, the action plan included a WIM event in November 2014 to report and widely communicate the programme's achievements and the future plans to the media and to reinforce WIM significance.

The 2nd Phase of the action plan also includes:

- Building partnerships with Chambers and government entities to have the support to expand the WIM program in other regions and to promote responsible consumption throughout the country.

- Implementation of self-regulation (WCS) in all commercial communications by first developing a selfregulation commercial code; in collaboration with the INV based on the WCS.

- Development of the Wine Information Council in Argentina (Scientific development) with the support of leading scientists from Argentina.

To assist in the implementation of the Argentinean WIM action plan in 2013/2014, a number of tools and actions were developed:

- Leaflets, Brochures;

- Stickers for wineries' visitors centers, wine shops, schools and vehicles;

- Bracelets to identify the designated driver;

- A video with the responsible drinking message based on the WIM common message;

- Cards to educate the consumer in events (consumers will be asked to write their commitment to action on these cards);

- A manual to train companies and wine academies;

- Sommeliers training;

- Annual talks to spread the WIM message and train people who work in wine tourism, restaurants and bars. 
Accountability is key in the WIM programme. Like all national coordinators, BAAC has reported the annual input and output of the WIM implementation in Argentina based on specific key performance indicators.

\section{Results}

In the short period of 1.5 years, BAAC has managed to successfully adapt, plan, implement and coordinate actions of the WIM programme in Argentina.

During this period, 25 wineries, two international companies not directly link to the wine sector, 6 Wine Academies from Buenos Aires and Mendoza, 1 Wine National Institution and 2 National Wine Chambers have also joined the WIM program in Argentina.

BAAC has developed four actions addressed to wine sector's human resources and marketing managers, tourism and oenotourism employees. BAAC has organized 43 dedicated events and events with WIM action and two launching events were organized last year.

With all these activities the WIM message has reached 14.228 people.

With the support of the entities that joined WIM, BAAC managed to disseminate more than 9000 WIM communication products and engaged 15 opinion leaders are committed to the programme.

WIM Programme was mentioned 80 times in the media in Argentina.

The successful implementation of the WIM program in Argentina has increased the interest of other countries in South America and facilitated the expansion of WIM outside the borders of the EU. In 2014, Vinos de Chile was the second country from South America to join WIM Aisbl and implement WIM in Chile.

The wineries that have joined WIM in Argentina, key people in the wine business and numerous entities have endorsed WIM and include the WIM message in their activities and in the press.

The knowledge and competences of the Argentinean wine professionals was increased thanks to workshops and seminar.

\section{Conclusions - discussions}

The WIM programme aims to promote moderation and responsibility in consumption of wine, supporting the message of wine as a premium product to be savoured slowly and in moderation, and to educate stakeholders and the public about the social and health risks of harmful consumption, while encouraging cultural change in the approach to consuming alcohol, and making moderation fashionable.

Bodegas de Argentina has proved to be very effective and successful in launching the implementation of the programme during this short period of time. It has been able to mobilize in Argentina a critical mass of the key leading organizations who committed to engage into the effective implementation of concrete WIM activities.
But no matter how short success of the programme, there are still a lot of steps to be taken in order to drive the necessary behavioural change in both the sector and society in order to contribute further to reduce the harm to individuals and the community linked to abusive and hazardous drinking.

The momentum that stems from the engagement and empowerment of the key stakeholders and the awareness raising over WIM and responsible drinking, must be seized to have the impact on the wine consumer.

The focus now turns to consumers between 25-35 years old, who respond and set the trends and shaping the future of our societies and that of the wine market.

The positive cooperation and partnership between the economic operators in the wine value chain, the authorities and all other relevant stakeholders in the civil society is necessary to make moderation a trend and responsibility a culture. As such the WIM programme implementation is a top strategic priority to promote the legitimate and sustainable development of a vibrant wine sector in Argentina.

Special thanks to Dr. Raúl Pastor for his scientific contribution to the programme in the area of wine and health. Thanks to Stylianos Filopoulos, Director of Wine in Moderation - Art the Vivre (WIM) Aisbl, José Ramón Fernández, Secretary General at CEEV (European Committee of Wine Companies) Ursula Fradera, Deutsche Weinakademie $\mathrm{GmbH}$, for their contribution and effort to the programme and their invaluable support for the implementation of WIM in Argentina.

\section{References}

[1] Wines of Argentina, http://www.winesofargentina.org/argent ina/regiones/

[2] Trade Data and Analysis (TDA). Bodegas de Argentina AC. (2007-2010). Per capita calculation based on population as of December 2009 published in US Central Intellegency Agency "CIA World Factbook". March 2010 and US Census Bureau "International Data Base", June 2010

[3] International Organisation of Vide and Wine) (OIV), StatOIV Extracts, http://www.oiv.int/ oiv/info/enstatoivextracts2

[4] Instituto Nacional deVitivinicultura (INV). Estadísticas vitivinícolas argentinas 1980 a 1999 (November, 2001)

[5] Josefina Rosner, Argentina Tiempo de Cosecha". Homenaje a la vitivinicultura en el Bicentenario de la Patria. (2010)

[6] World Health Organization (WHO) Global Health Observatory, Global Information System on Alcohol and Health (GISAH)

[7] World Health Organization (WHO), Global status report on alcohol and health, 138 (2014)

[8] WIM Aisbl, Wine in Moderation-Art de Vivre Programme Implementation Report 2011-2013 (2014) 